\title{
Health economic evidence of $5 \%$ lidocaine medicated plaster in post-herpetic neuralgia
}

This article was published in the following Dove Press journal:

ClinicoEconomics and Outcomes Research

22 November 2013

Number of times this article has been viewed

\author{
Hiltrud Liedgens' \\ Marko Obradovic' \\ Mark Nuijten² \\ 'Grunenthal GmbH, Aachen, \\ Germany; ${ }^{2}$ Ars Accessus Medica, \\ Amsterdam, the Netherlands
}

Correspondence: Hiltrud Liedgens Grunenthal GmbH, Zieglerstrasse 6, Aachen, 52099, Germany

Tel +4924I 5692679

Fax +49 24I 5692986

Email hiltrud.liedgens@grunenthal.com
Background: Post-herpetic neuralgia (PHN) is the most common and most debilitating complication of herpes zoster, and involves considerable associated costs.

Objective: This paper presents results from nine health economic studies undertaken in eight European countries that compared lidocaine medicated plaster with gabapentin and/or pregabalin in PHN. It aims to support the increasing need for published cost-effectiveness data for health care decision-making processes in Europe.

Methods: All studies were based on a similar core Markov model with data derived from clinical trials, local Delphi panels, and official national price and tariff lists. The main outcome measure was cost per quality-adjusted life year gained; time without pain or intolerable adverse events was also included as a secondary outcome measure. All studies focused on an elderly population of patients with PHN who had insufficient pain relief with standard analgesics and could not tolerate or had contraindications to tricyclic antidepressants.

Results: Despite considerable differences in many of the variables used, the results showed remarkable similarity and suggested that use of lidocaine medicated plaster offered cost-savings in many of the countries studied, where it proved a highly cost-effective alternative to both gabapentin and pregabalin.

Conclusion: Lidocaine medicated plaster is a cost-effective alternative to gabapentin and pregabalin in the treatment of PHN. These savings are largely the result of the superior safety profile of the lidocaine medicated plaster.

Keywords: post-herpetic neuralgia, zoster, cost-effectiveness, lidocaine, plaster

\section{Background}

Post-herpetic neuralgia (PHN) is prolonged neuropathic pain persisting for over 3 months after an attack of acute herpes zoster. ${ }^{1}$ It is the most common complication of shingles and develops in up to $34 \%$ of sufferers, ${ }^{2}$ with estimates of prevalence ranging from 500,000 to 1 million. ${ }^{3}$ The burden of PHN can be considerable; it has been reported to be associated with severe psychosocial dysfunction, including impaired sleep, decreased appetite, and diminished libido that affects patients' quality of life, ${ }^{4,5}$ normal daily activities, and social activities. ${ }^{6}$ Older individuals, who are most susceptible to $\mathrm{PHN}$, are at greater risk for complications such as fatigue, anorexia, weight loss, insomnia, depression, difficulty concentrating, and difficulty performing activities of daily living. ${ }^{7}$

Economic data suggest that the cost of PHN is also considerable. In Italy, for example, direct cost per episode of PHN has been shown to be $€ 446$ for outpatients, rising to $€ 2,806$ for inpatient care, with the total economic burden of zoster plus PHN in Italy estimated at $€ 41.2$ million. $^{8}$ 


\section{Current management of PHN}

Guidelines for the management of PHN are included in most guidelines for neuropathic pain; for example in the Special Interest Group on Neuropathic Pain of the International Association for the Study of Pain (NeuPSIG) ${ }^{9}$ and the European Federation of Neurological Societies (EFNS). ${ }^{10}$ Specific guidelines for the management of PHN have been issued by the American Academy of Neurology (AAN). ${ }^{11}$

Recommended first-line treatments for PHN include tricyclic antidepressants (TCAs), gabapentin, pregabalin, or the topical 5\% lidocaine medicated plaster. Opioids, tramadol, capsaicin cream, and the capsaicin $8 \%$ patch are recommended as either second- or third-line therapies in different guidelines. ${ }^{12}$ The EFNS updated guidelines recommend TCAs or gabapentin/pregabalin as first-line treatment in PHN and topical 5\% lidocaine medicated plaster as first-line in the elderly, especially when there are concerns regarding the CNS side effects of oral medications. ${ }^{10}$

The side effects of many systemic treatments, particularly TCAs, can be limiting and can compromise quality of life ${ }^{13}$ and patient compliance. ${ }^{12,14}$ TCAs can also cause significant dysrhythmias in patients with conduction abnormalities. ${ }^{15}$ As a result, clinicians are recommended to prescribe TCAs cautiously to patients with a history of congenital QT syndrome, cardiovascular disease, or hypokalemia. ${ }^{16}$ Also, many patients with PHN are not optimally managed ${ }^{10,17,18}$ and can undergo several months of "trial and error" treatment. ${ }^{9}$

Gabapentin and pregabalin are the most commonly prescribed systemic agents for PHN. ${ }^{18}$ Gabapentin (Neurontin ${ }^{\circledR}$, Pfizer, New York, NY, USA) has dose-limiting side effects such as somnolence, dizziness, and ataxia, which are of concern in the elderly, who are more prone to falls. ${ }^{19}$ These side effects may result in undertreatment; this suspicion is supported by market research analyses of prescription data from five European countries, which suggests that prescriptions are often on the lower end of the dose range $(978 \mathrm{mg} /$ day; range, 793-1,247 mg/day versus indicated dose 900-3,600 mg/day) (unpublished data, IMS MAT, September 2012). Gabapentin has analgesic efficacy in established PHN, where pooled trial results have given a number needed to treat (NNT; 50\% pain reduction) of 4.39 (3.34-6.07). ${ }^{20,21}$ Clinical trial data suggest that gabapentin results in $30 \%$ of patients achieving $50 \%$ pain relief. ${ }^{22}$ Pregabalin (Lyrica ${ }^{\circledR}$, Pfizer) is in the same class as gabapentin and has a similar side effect profile. ${ }^{23}$ The relative risks for these events increases with $\operatorname{dose}^{24}$ and, as with gabapentin, this may result in undertreatment, again supported by prescription data showing the mean daily dose of pregabalin across five European countries is at the lower end of the dose range (188 mg/day; range 163-250 mg/day versus the indicated dose $150-600 \mathrm{mg} /$ day). Pooled results of two studies ${ }^{25,26}$ showed the NNT (50\% pain reduction) with pregabalin was 4.93 (3.66-7.58). In addition, a post hoc analysis of eleven clinical studies of pregabalin in patients with diabetic peripheral neuropathy (DPN) or PHN showed significant improvements in pain and clinically meaningful pain relief in all age groups. ${ }^{24}$

Topical treatments for PHN include the capsaicin patch and the $5 \%$ lidocaine medicated plaster (LMP; Versatis ${ }^{\circledR}$, Grünenthal GmbH, Aachen, Germany). The capsaicin patch is licensed for the symptomatic relief of PHN once skin lesions have healed. Results from two studies (709 participants in total) that compared a single high dose (8\%) capsaicin patch with placebo suggested the NNT, for $\geq 30 \%$ pain relief over 12 weeks, was 12 (6.4-70). ${ }^{27}$ The most common side effects of the patch are local skin reactions and application site pain; this can be severe in some patients and requires pretreatment with lidocaine cream or oral opioid analgesics. ${ }^{28,29}$

\section{Lidocaine medicated plaster in post-herpetic neuralgia}

The LMP consists of 5\% lidocaine (w/w) in an aqueous adhesive on a soft hydrogel dressing. It is approved by both the European Medicines Agency (EMA) and the US Food and Drug Administration (FDA) for the treatment of PHN.

Evidence from six published randomized controlled trials, ${ }^{31-36}$ six open-label, nonrandomized studies, ${ }^{13,36-40}$ and one retrospective follow-up survey ${ }^{41}$ shows it to be well tolerated and effective. Current data suggest that LMP may be superior to pregabalin and as efficacious as gabapentin. A recent headto-head comparative study versus pregabalin ${ }^{13}$ has shown that LMP has a superior efficacy and safety profile, with greater improvements in patient satisfaction and quality of life. In that study, ${ }^{13}$ adults with PHN or painful diabetic peripheral neuropathy received LMP applied to the most painful skin area or twice-daily pregabalin capsules titrated to effect. The primary endpoint was response rate at 4 weeks, defined as reduction averaged over the last 3 days from baseline of $\geq 2$ points or an absolute value of $\leq 4$ points on the elevenpoint Numerical Rating Scale (NRS-3). Results for patients with PHN showed the percentage of responders was greater in those receiving LMP (63.3\% versus $46.8 \%$ for those receiving pregabalin), and that mean change from baseline in the EuroQol health index (EQ-5D) estimated health state was 0.12 for recipients of LMP versus zero for pregabalin recipients. In addition, patients' global impression of change (PGIC) was rated as "very much/much improved" in 51\% 
of LMP recipients versus $42 \%$ of pregabalin recipients; clinicians' global impression of change (CGIC) was rated as "very much/much improved" in 53\% of LMP versus 33\% of pregabalin recipients and patients rated their treatment satisfaction as "excellent" in 16\% of LPM recipients versus $7 \%$ of pregabalin recipients. The adverse event (AE) profiles of the two treatments were markedly different: 48 AEs were observed in $18.7 \%$ of patients receiving the LMP, compared with 194 AEs in 46.4\% of pregabalin recipients. Drug-related AEs occurred in $5.8 \%$ of those receiving the LMP compared with $41.2 \%$ in those receiving pregabalin. The most common drug-related AEs in the LMP recipients were headache (1.3\%) and application site irritation (1.3\%). Overall, 5.8\% patients receiving LMP experienced an AE leading to study discontinuation, compared with $25.5 \%$ of patients receiving pregabalin. Among these, $2.6 \%$ in the LMP group and $23.5 \%$ in the pregabalin group discontinued because of drug-related AEs.

In addition, a quantitative systematic review of analgesic therapy has suggested that LMP has superior efficacy to pregabalin: the NNT for pain relief was 2.00 (95\% confidence interval [CI] 1.43-3.31) for LMP compared with 4.93 (95\% CI 3.66-7.58) for pregabalin. ${ }^{42}$ Similarly, a randomized placebo-controlled study of LMP in PHN and peripheral neuropathic pain syndromes gave an NNT of 4.4, which compares well with other treatments for PHN. ${ }^{30}$ Another systematic review has suggested that LMP and gabapentin have similar effects on pain relief, and that LMP is more effective than capsaicin and pregabalin. ${ }^{43}$

Pain is known to impact severely on quality of life, and LMP has been shown to improve pain interference with quality of life in a number of studies involving patients with different neuropathic pain conditions. ${ }^{44}$ In one study, 332 individuals with PHN treated with LMP reported significantly lower mean scores on the Brief Pain Inventory Short Form (ie, improved quality of life) across all domains compared with baseline. ${ }^{37}$ Also, a prospective, multicenter, noninterventional observational study in Germany found major improvements in quality of life in 922 patients with chronic neuropathic pain using LMP over 12 weeks. ${ }^{45}$ Long-term use of the LMP has been reported and has been found to be both effective and well tolerated. ${ }^{40,46,47}$ In one study, 102 patients from a 12 month study were included in an extension phase of up to 3 years. Twenty-seven patients $(26.4 \%)$ were still using an LMP after a total of 4 years. At the final visit, LMP was rated to be good by $91 \%$ of physicians and $89 \%$ of patients; there was no evidence of a reduced analgesic effect or an increase in drug-related adverse events with long-term treatment. ${ }^{47}$
This overview reports on the value of LMP from a health economics point of view versus current standard of care. The results from nine cost-effectiveness or cost-utility studies from Europe examining the comparative benefit of this topical treatment are presented.

\section{Cost-effectiveness of LMP in PHN: the European experience}

Analytical models for cost-effectiveness analysis in PHN are typically Markov-type models because costs and outcomes usually span a significant period of time. Markov models group patients into a finite number of health states, with time progressing in equal increments. All events are represented as transitions from one state to another with a certain probability. Transition probabilities are calculated from epidemiological and/or clinical data. Spending one cycle in a given state is associated with a certain cost and a defined utility outcome reflecting the quality of life.

\section{Methodology}

Nine cost-effectiveness studies were undertaken in different European countries (UK, Scotland, Germany, Spain, the Netherlands, Sweden, Austria, and Portugal). As no head-to-head study was available for the early models, ${ }^{48-52}$ transition probabilities were derived from Delphi panel discussion supplemented by data from two clinical trials..$^{21,37}$ The methodology used in these early models is described in detail in Dakin et al. ${ }^{48}$ For the later models, ${ }^{53-56}$ a head-to-head clinical trial versus pregabalin ${ }^{13}$ was available; transition probabilities were based on the results from this study. Details on the methodology used in these later models are described in Ritchie et al. ${ }^{53}$

A Markov model for LMP in PHN was developed using TreeAge Pro software (TreeAge Software Inc, Williamstown, MA, USA) to calculate the costs and clinical utility outcomes of LMP relative to gabapentin and/or pregabalin for $\mathrm{PHN}$ in terms of the cost per quality-adjusted life years (QALYs) gained. The two core models described above ${ }^{48,53}$ were adapted by implementing local resource use and costs to allow cost-effectiveness analyses reflecting different country situations. The main branch of the model was designated for each treatment strategy to be investigated, with identical subsequent branches, with differences in probabilities as described above and with different resource use and costs.

The model structure is shown in Figure 1. The model had a time horizon of 6 months to allow for extrapolation beyond the time horizon of clinical trials data and thus for patient discontinuation from treatment at any time. The main outcome measure of the model was cost per QALY gained. 


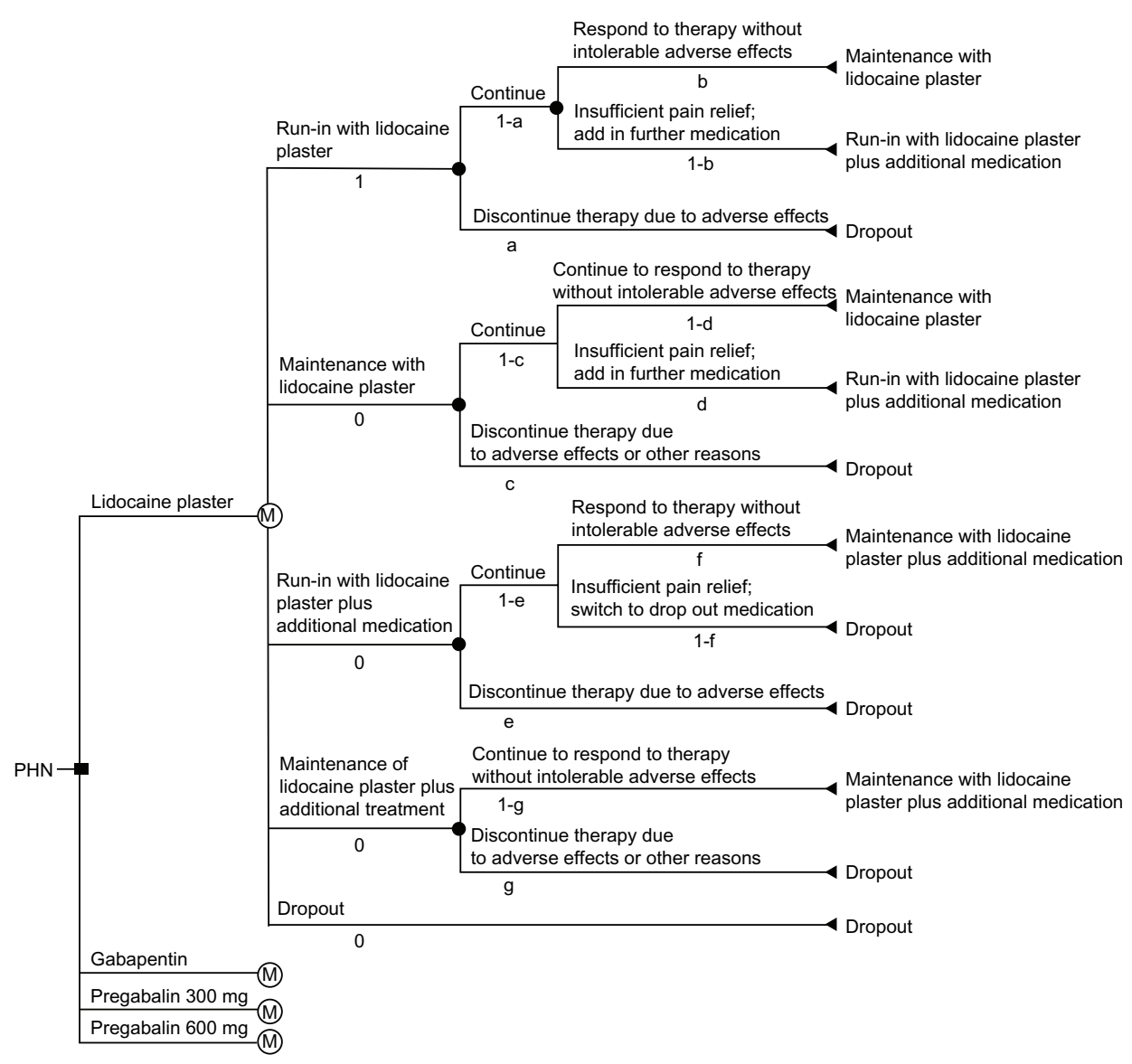

Figure I Basic decision tree structure for the Markov model.

Notes: Lidocaine medicated plaster; Versatis ${ }^{\circledR}$, Grünenthal GmbH, Aachen, Germany. a, discontinue the lidocaine plaster during the run-in phase; b, remain on the lidocaine plaster monotherapy after the run-in phase; c, discontinue the lidocaine plaster during the maintenance phase; $d$, add in additional medication during the lidocaine plaster maintenance phase; e, cease the lidocaine plaster during the run-in with the lidocaine plaster plus additional medication; $f$, remain on the lidocaine plaster after the run-in phase of the additional medication; g, discontinue the lidocaine plaster during the maintenance phase with additional treatment.

Abbreviations: PHN, post-herpetic neuralgia; M, Markov node.

An additional outcome measure was time without pain or intolerable adverse events as measured by discontinuation because of drug-related AEs, which is a modification of the "time without symptoms or toxicity" (TWIST) analysis. The number of months without pain or intolerable AEs was based on the average percentage of the period modeled during which a patient experienced sufficient pain relief without intolerable AEs. Run-in phases were incorporated because patients starting treatment with gabapentin and pregabalin required an initial titration to the therapeutic dose. Each arm of the basic model had five disease states, and patients moved from one state to another according to their response to treatment or any adverse effects they experienced.

The disease states were:

- run-in with lidocaine, gabapentin or pregabalin.

- maintenance with lidocaine, gabapentin or pregabalin.

- run-in with lidocaine plus additional medication, gabapentin plus additional medication, or pregabalin plus additional medication.
- maintenance with lidocaine plus additional medication or gabapentin plus additional medication or pregabalin plus additional medication.

- dropout: this state encompasses all patients who experienced intolerable adverse effects with lidocaine/ gabapentin/pregabalin or had pain relief despite use of concomitant medication; in this state, patients are assumed to cease lidocaine/gabapentin/pregabalin and switch to alternative medication.

Patients entering the model received either LMP or gabapentin or pregabalin and remained within the run-in state for 30 days. After this time, patients experiencing intolerable AEs ceased treatment and entered the dropout state, where they switched to alternative therapies; those with insufficient pain relief added other medications. Patients with adequate pain relief and no intolerable AEs (responders) were assumed to enter the maintenance treatment phase, where they remained unless they discontinued therapy or ceased to have sufficient pain relief. 
Patients receiving additional medication first entered a further 30 day run-in phase during which the additional medication was titrated. They then progressed to the maintenance disease state or dropped out and switched to other treatments if they experienced intolerable AEs or insufficient pain relief. Patients who began treatment with an additional medication and experienced intolerable AEs or insufficient pain relief were assumed not to go back to the original single-agent treatment with gabapentin, pregabalin, or LMP, but to enter the dropout disease state, where all patients switched to other medications such as acetaminophen, tramadol, capsaicin, or codeine and would remain in this state for the remainder of the period modeled. The types and doses of switch medications were estimated by a Delphi panel and were taken into account in cost calculations.

As outlined earlier, transition probabilities for the models were based on efficacy data from clinical trials (Table 1) and discussion by Delphi panels. In each country, pain experts and general practitioners were eligible to join the Delphi panels if they had treated at least five patients with PHN in the past year and had had experience with the investigated treatments. Each panel member completed a questionnaire addressing the types and doses of concomitant or switch medications required, and resource use associated with each health state. Consensus on the most realistic value for each parameter was then reached at a panel meeting. Participants were reimbursed for their time and travel expenses and were aware of which company was sponsoring the study, but had no other known conflicts of interest.

Drug costs used in the models were taken from official price tariffs in each country. Utilities were derived from a study by Cepeda and Farrar ${ }^{57}$ in patients with neuropathic pain. These utilities were adapted based on the clinical experience of the Delphi panels and applied to each disease state within each arm of the model. Scenario analyses and extensive sensitivity analyses including probabilistic sensitivity analyses (PSA) were undertaken to determine the robustness of results.

All studies using this model focused on an elderly population of patients with PHN who had insufficient pain relief with standard analgesics and could not tolerate or had contraindications to TCAs, thus reflecting the usual treatment population for the LMP or pregabalin.

\section{Results}

A summary of the individual studies is presented in Table 2. The pooled results from all studies outlined in Table 3 show that LMP is a cost-effective method of obtaining sustained relief from localized neuropathic pain associated with PHN, compared with gabapentin and pregabalin in all health care settings investigated.
Results from the early UK study showed the LMP was dominant to gabapentin and the PSA closely matched the basecase results. ${ }^{48}$ The incremental cost-effectiveness ratio (ICER) was significantly below the threshold of $£ 20,000$ to $£ 30,000$ per QALY, and the $95 \%$ CI ranged from LMP being dominant over gabapentin to costing $£ 2,163$ per QALY gained.

In Scotland, results showed the LMP was associated with an ICER of $£ 3,767$ relative to gabapentin and PSA demonstrated $98.7 \%$ confidence that LMP is cost-effective relative to gabapentin at a $£ 20,000$ per QALY threshold and $65 \%$ confidence at a $£ 5,000$ per QALY threshold. ${ }^{49}$ The scenario analysis using 1.03 LMPs per day showed LMP as dominant to gabapentin with a $99.8 \%$ confidence at a $£ 20,000$ per QALY threshold. The model relative to pregabalin showed LMP costs $£ 674$ per QALY relative to pregabalin $300 \mathrm{mg}$ and $£ 434$ per QALY relative to pregabalin $600 \mathrm{mg} .{ }^{50}$ The PSA demonstrated $99.9 \%$ confidence that LMP is cost-effective relative to $300 \mathrm{mg}$ pregabalin and $99.8 \%$ confidence that it is cost-effective relative to $600 \mathrm{mg}$ pregabalin at a $£ 20,000$ per QALY threshold. Modified TWIST analysis gave costs of $£ 27$ and $£ 18$ per additional month with sufficient pain relief and no intolerable side effects relative to pregabalin $300 \mathrm{mg}$ and $600 \mathrm{mg}$, respectively.

Results from Germany showed an ICER of $€ 3,453$ relative to gabapentin and dominance relative to pregabalin. ${ }^{51}$ PSA demonstrated a $99.36 \%$ confidence that LMP is the most clinically effective treatment and a $99.09 \%$ chance that LMP is the most cost-effective treatment of the four therapies considered in the analysis if the Gesetzlichen Krankenversicherung (GKV; German Health Insurance Ordinance) is willing to pay at least $€ 20,000 / \mathrm{QALY}$ gained. The modified TWIST analysis showed the ICER for LMP to be $€ 137$ per additional month without adverse effects relative to gabapentin, and $€ 35$ per additional month without adverse effects or symptoms relative to pregabalin $300 \mathrm{mg}$, and dominance over $600 \mathrm{mg}$ pregabalin.

In the Netherlands, the model showed a cost per QALY of $€ 908$ relative to gabapentin, $€ 1,161$ relative to $300 \mathrm{mg}$ pregabalin and dominance relative to $600 \mathrm{mg}$ pregabalin..$^{52}$ The PSA demonstrated a $99 \%$ confidence that LMP is costeffective relative to gabapentin, $300 \mathrm{mg}$ and $600 \mathrm{mg}$ pregabalin, if the Dutch society is willing to pay at least $€ 20,000$ to gain one QALY. The LMP cost $€ 44$ per additional month with sufficient pain relief and no intolerable side effects relative to gabapentin, $€ 65$ relative to $300 \mathrm{mg}$ pregabalin and was dominant relative to $600 \mathrm{mg}$ pregabalin.

In the second, subsequent modeling study undertaken in the UK comparing LMP with pregabalin, the average patient treated with LMP accrued 0.321 QALYs over the 6 month period versus 0.254 for pregabalin, with a cost per QALY of $£ 2,925$ relative to pregabalin. ${ }^{53}$ Results for the ICER from 


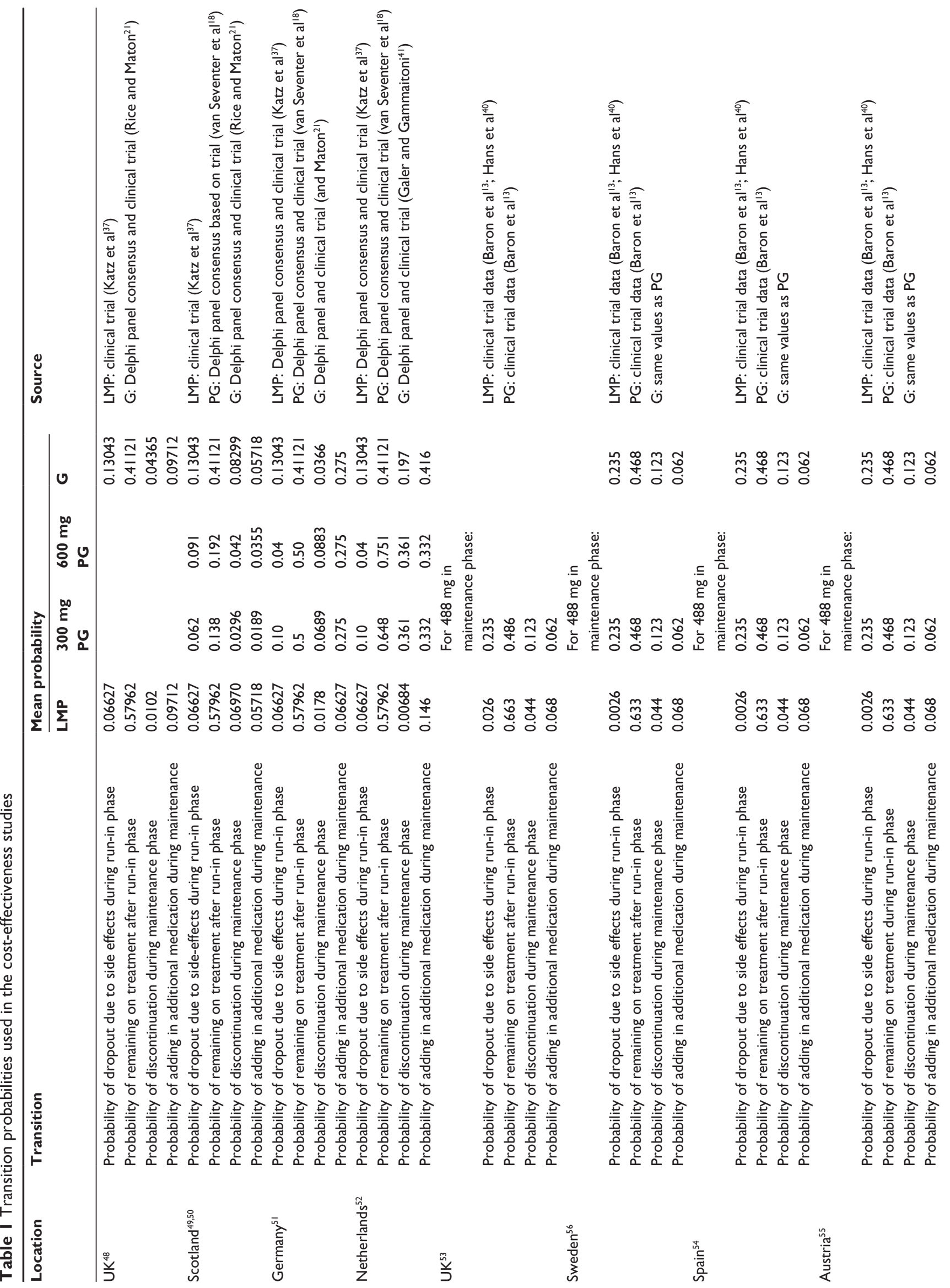


the scenario analysis using 1.1 LMP per day showed LMP as dominant relative to pregabalin. The PSA results closely matched those of the base-case and indicated an almost $100 \%$ confidence that LMP is the most cost-effective strategy if society is willing to pay at least $£ 15,000$ to gain one QALY (Figure 2). The model also predicted that within the same time period, patients treated with LMP would have a mean of 4.29 months $(71.5 \%$ of the total period modeled) with adequate pain relief and no intolerable AEs compared with a mean of 2.74 months ( $45.6 \%$ of the total period modeled) for pregabalin giving an ICER of $£ 126$ per additional symptomfree month relative to pregabalin.

In Spain, the base-case analysis showed an ICER for LMP compared with gabapentin and pregabalin of $€ 7,009$ and $€ 4,230$ per QALY gained, respectively ${ }^{54}$ Scenario analysis with a lower LMP consumption of 1.1 per day showed the ICER decreased to $€ 3,525$ per QALY gained compared with gabapentin and to $€ 742$ per QALY gained relative to pregabalin. PSA showed that at acceptable cost-effectiveness thresholds of $€ 20,000-30,000$ per QALY, the lidocaine plaster had a high probability of being cost-effective compared with both gabapentin and pregabalin.

In Sweden, similar results were obtained: the cost per QALY was $€ 2,520$ relative to $300 \mathrm{mg}$ pregabalin, and scenario analysis using 1.03 LMPs per day showed the plaster was dominant to $300 \mathrm{mg}$ pregabalin. ${ }^{56}$ The PSA demonstrated over $90 \%$ confidence that LMP is cost-effective relative to pregabalin, costing less than SEK 180,000 per QALY gained relative to pregabalin.

The base-case analyses for Austria and Portugal showed that both costs and QALYs were higher with LMP compared with pregabalin but with a highly acceptable ICER ${ }^{55}(€ 9,899$ and $€ 4,663$ per QALY gained relative to pregabalin for 1.71 and 1.03 plasters per day in Austria and $€ 1,112$ per QALY gained relative to pregabalin for 1.71 plasters per day and dominance with 1.03 plasters per day in Portugal). The PSA showed that at acceptable cost-effectiveness thresholds LMP had a high probability of being cost-effective compared with pregabalin both in Austria and Portugal. Results for Portugal also showed that there was an approximately $40 \%$ chance that LMP was both more effective and less expensive than pregabalin.

\section{Discussion}

This paper draws together a number of similar costeffectiveness analyses all designed to assess the costs associated with LMP in PHN as compared with gabapentin and pregabalin. All studies were based on a similar Markov model, originally designed for the UK health care system, 


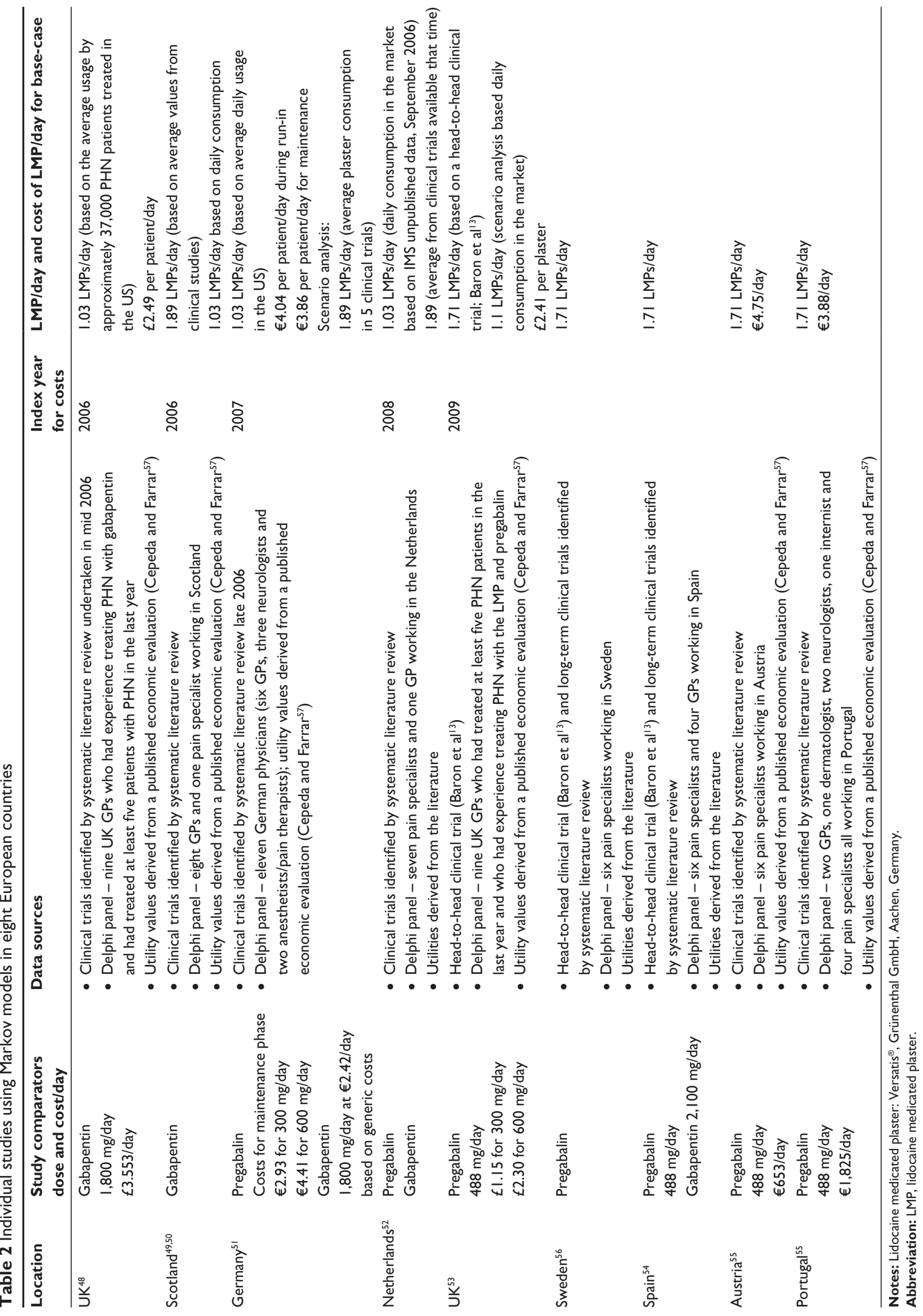


Table 3 Cost-effectiveness of LMP using Markov modeling in ten European studies

\begin{tabular}{|c|c|c|c|c|c|}
\hline Study & $\begin{array}{l}\text { Total treatment } \\
\text { cost/patient } \\
\text { (6 months) }\end{array}$ & $\begin{array}{l}\text { Accrued } \\
\text { QALYs } \\
\text { (6 months) }\end{array}$ & ICER (cost/QALY) & $\begin{array}{l}\text { Symptom } \\
\text { free time } \\
\text { (months) }\end{array}$ & $\begin{array}{l}\text { ICER (cost/ } \\
\text { additional symptom } \\
\text { free month) }\end{array}$ \\
\hline \multicolumn{6}{|l|}{$\mathrm{UK}^{48}$} \\
\hline LMP I.03/day & $£ 549$ & 0.2991 & Dominant to gabapentin $(£ 2,163)$ & & \\
\hline LMP I.89/day & $£ 845$ & 0.2991 & $£ 2,543$ & & \\
\hline Gabapentin & $€ 718$ & 0.2489 & & & \\
\hline \multicolumn{6}{|l|}{ Scotland ${ }^{49}$} \\
\hline LMP I.89/day & $£ 958$ & 0.2922 & $£ 3,767$ to gabapentin & & \\
\hline LMP I.03/day & $€ 681$ & 0.2922 & Dominant to gabapentin $(£|3,4| 5)$ & & \\
\hline Gabapentin & $£ 789$ & 0.2473 & & & \\
\hline \multicolumn{6}{|l|}{ Scotland ${ }^{50}$} \\
\hline LMP I.03/day & $€ 681$ & 0.292 & $£ 434$ to pregabalin & 4.45 & $£ \mid 8$ to pregabalin \\
\hline Pregabalin (600 mg) & $£ 655$ & 0.231 & & 2.98 & \\
\hline \multicolumn{6}{|l|}{ Germany ${ }^{51}$} \\
\hline LMP I.03/day & $€ 911$ & 0.300 & $€ 3,453$ to gabapentin & 4.06 & $€ I 37$ to gabapentin \\
\hline Gabapentin & $€ 728$ & 0.247 & LMP dominant to pregabalin & 2.72 & Dominant to pregabalin \\
\hline Pregabalin (600 mg) & $€ 977$ & 0.256 & & 3.22 & \\
\hline \multicolumn{6}{|l|}{ Netherlands ${ }^{52}$} \\
\hline LMP I.03/day & $€ I, 180$ & 0.401 & $€ 908$ to gabapentin & & $€ 44$ to gabapentin \\
\hline Gabapentin & $€ I,|2|$ & 0.336 & LMP dominant to pregabalin & & Dominant to pregabalin \\
\hline Pregabalin (600 mg) & $€ I, 386$ & 0.349 & & & \\
\hline \multicolumn{6}{|l|}{ UK $^{53}$} \\
\hline LMP I.7I/day & $£ 980$ & 0.321 & $£ 2,925$ to pregabalin & 4.287 & $£ 126$ \\
\hline LMP I.I/day & $£ 756$ & 0.321 & LMP dominant to pregabalin & 2.737 & \\
\hline Pregabalin & $€ 784$ & 0.254 & & & \\
\hline \multicolumn{6}{|l|}{ Sweden ${ }^{56}$} \\
\hline LMP I.7I/day & $€ 2,263$ & 0.428 & $€ 2,520$ to pregabalin & & \\
\hline LMP I.03/day & $€ I, 904$ & 0.340 & LMP dominant to pregabalin & & \\
\hline Pregabalin (300 mg) & $€ 2,04$ I & & & & \\
\hline \multicolumn{6}{|l|}{ Spain $^{54}$} \\
\hline LMP I.7I/day & $€ 1,725$ & 0.428 & $€ 7,009$ to gabapentin & 4.6 & $€ 307$ to gabapentin \\
\hline LMP I.I/day & $€ I, 4 \mid 4$ & 0.428 & $€ 4,230$ to pregabalin & 4.6 & $€ \mid 85$ to pregabalin \\
\hline Gabapentin (generic) & $€ 1,100$ & 0.339 & $€ 3,525$ to gabapentin & 2.6 & \\
\hline Pregabalin (488 mg) & $€ I, 348$ & 0.339 & $€ 742$ to pregabalin & 2.6 & \\
\hline \multicolumn{6}{|l|}{ Austria $^{55}$} \\
\hline LMP I.7I/day & $€ I, 534$ & 0.428 & $€ 9,899$ & 4.6 & $€ 433$ \\
\hline LMP I.I/day & $€ I, 068$ & 0.428 & $€ 4,663$ & 4.6 & $€ 204$ \\
\hline Pregabalin (488 mg) & $€ 653$ & 0.339 & & 2.6 & \\
\hline \multicolumn{6}{|l|}{ Portugal $^{55}$} \\
\hline LMP I.7I/day & $€ 1,924$ & 0.428 & $€ \mathrm{I}, \mathrm{I} / 2$ & 4.6 & $€ 49$ \\
\hline LMP I.I/day & $€ 1,585$ & 0.428 & LMP dominant to pregabalin & 4.6 & Dominant \\
\hline Pregabalin (488 mg) & $€ 1,825$ & 0.339 & & 2.6 & \\
\hline
\end{tabular}

Notes: Lidocaine medicated plaster: Versatis ${ }^{\circledR}$, Grünenthal GmbH, Aachen, Germany.

Abbreviations: LMP, lidocaine medicated plaster; QALY, quality-adjusted life years; ICER, incremental cost-effectiveness ratio.

but which was adapted for other national systems in Europe. Although transition probabilities evolved as new comparative data became available (non-head-to-head studies, Delphi panel estimations, and head-to-head studies), and index costs and dosages were adapted according to local settings, the overall results are remarkably similar and show that LMP is a highly cost-effective treatment for $\mathrm{PHN}$, with costs per QALY falling within the willingness to pay thresholds of all countries studied. Extensive sensitivity analyses were undertaken in all studies; these analyses demonstrated that the findings were robust and that the outcome was not sensitive to the underlying assumptions of the model. The results highlight the need for prescribers to balance pain relief with side effects in PHN and show that the better safety profile associated with LMP can translate into real cost savings when included in the model used.

The sensitivity analyses demonstrated that LMP dose ie, number of plasters used per day - significantly impacted the cost-effectiveness result in most countries. Doses used in the different analyses reflected typical doses used in clinical trials and average actual doses reported from clinical practice; these ranged from 1.03 to 1.89 plasters per day. The 


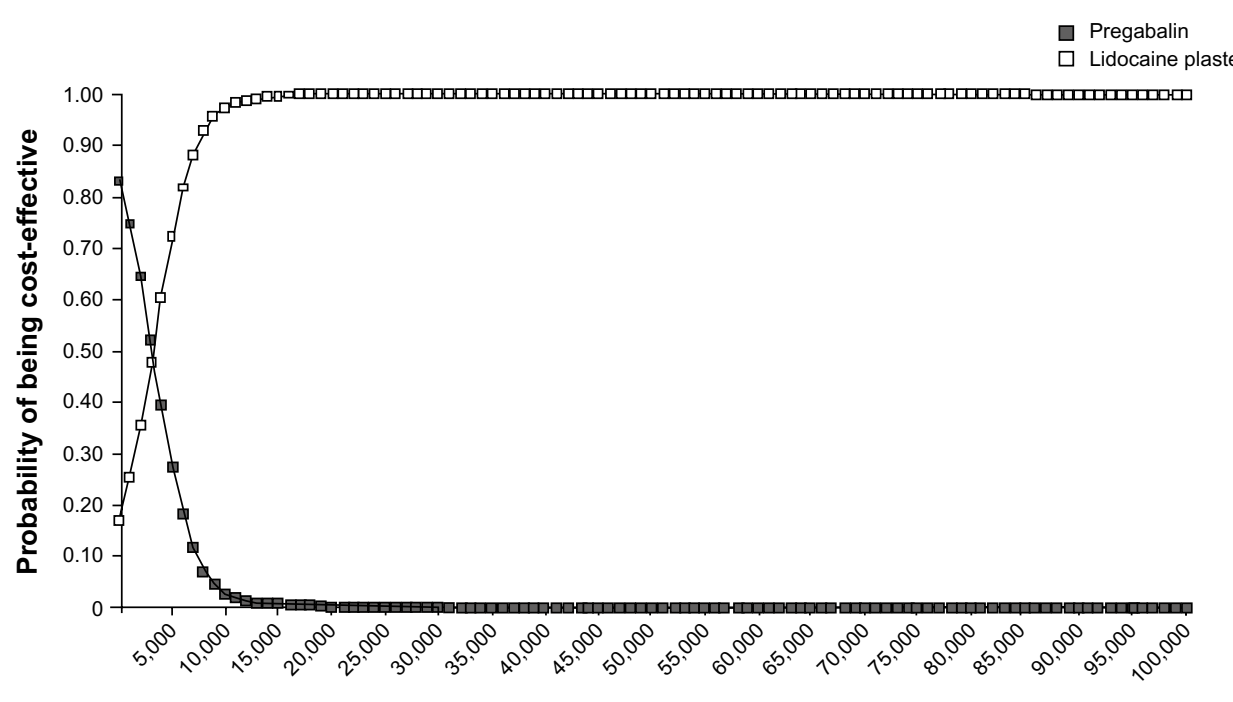

Cost-effectiveness threshold (£)

Figure 2 CE acceptability curve for LMP relative to pregabalin in the UK.

Notes: Lidocaine medicated plaster: Versatis ${ }^{\circledast}$, Grünenthal GmbH, Aachen, Germany. Reproduced with kind permission Springer Science+Business Media. Nuijten M, Hidalgo A, Obradovic M, Liedgens $\mathrm{H}$. Cost-effectiveness of a lidocaine plaster relative to gabapentin and pregabalin in the treatment of postherpetic neuralgia in Spain. Value Health. 2010;13(7):A468. ${ }^{54}$

Abbreviations: CE, cost effectiveness; LMP, lidocaine medicated plaster.

size of the painful area defines the number of plasters used per day, whereby the label allows up to three $140 \mathrm{~cm}^{2}$ plasters per day for the duration of pain (Versatis ${ }^{\circledR}$ SPC; Grunenthal Ltd, Stokenchurch, UK). In a retrospective, observational study investigating the efficacy and safety of treating refractory chronic neuropathic pain with LMP in patients attending pain centers in France, the majority (74\%) of patients used only one plaster daily and only $13.5 \%$ used two plasters per day. ${ }^{46}$ This suggests that the data predicting the cost-effectiveness resulting from using 1.03 LMPs per day may more closely reflect actual usage.

The results from several analyses included in this review suggested that LMP was a cost-effective treatment in all countries. Moreover, in some scenarios it was shown to be a dominant strategy, ie, being both more effective and less costly versus comparators. Several cost-effectiveness studies for treatment intervention in PHN have been published, but they include different efficacy outcomes, different formulations and the results are often conflicting. One large study designed to compare the topical $8 \%$ capsaicin patch with products currently used in the treatment of PHN from a managed care perspective and used a 12-month Markov model with monthly cycles; the efficacy parameter was the proportion of patients achieving at least a $30 \%$ improvement in PHN pain. ${ }^{58}$ The study included data from multiple clinical trials taken from literature searches, although no head-to-head studies were used. Products compared included TCAs, LMP, duloxetine, gabapentin, and pregabalin, with costs taken from a US internet site, drugstore.com. The result supports the results covered in this review, ${ }^{58}$ since they found the highest cost-effectiveness was achieved with LMP and $8 \%$ capsaicin patch. There was no significant difference in effectiveness rates between the plasters, and both had significantly greater effectiveness rates compared with TCAs, gabapentin, duloxetine, and pregabalin. However, the number of LMPs used per day in this model was three, considerably more than used in the studies included in this overview.

Smith and Roberts ${ }^{59}$ in the US constructed a Markov model to estimate the incremental cost-effectiveness of sequential management strategies for established PHN in hypothetical cohorts of 70-year-old patients using various sequences of six drugs: gabapentin, topical LMP, TCAs, opioid analgesics, pregabalin, and tramadol. LMP was considered only in the separate analyses for patients with localized pain. The authors found that, for these patients, LMP was favored as a reasonable and cost-effective first-choice therapy.

Health care utilization analyses also support the costeffectiveness of LMP and suggest that the costs of treatment with LMP are less than those with gabapentin or pregabalin. A study undertaken in the US to compare the annual health care expenditures of commercially insured patients using either LMP or gabapentin as analgesia for many pain conditions, including PHN, showed that patients using LMP spent $\$ 1,780$ per patient per year less than those on branded gabapentin. ${ }^{39}$ Further, the study showed that LMP was still less costly when it was compared with generic gabapentin. 
Another study undertaken in the US has compared the resource utilization and costs of LMP relative to gabapentin and pregabalin in PHN as identified by Medicaid claims data. ${ }^{60}$ Results showed that during the 6 month study period prescription costs were similar for matched patients receiving either LMP or gabapentin/pregabalin but that the PHN-related medical costs were lower in those using LMP compared with those receiving gabapentin/pregabalin $(\$ 145$ versus $\$ 353, P=0.12$ ).

There is an increasing movement toward the need for costeffectiveness data in the decision-making process in Europe; for example, health technology assessment procedures in the UK, the Netherlands, Scotland, Sweden, and Portugal all require cost-effectiveness data. This is usually provided as cost per QALY, and values ranging from $\$ 50,000$ to $\$ 100,000$ are sometimes used as a threshold in the US and in the UK (and in some countries in Europe). NICE has adopted a cost-effectiveness threshold range of $£ 20,000$ to $£ 30,000$ per QALY gained. While reimbursement decisions should incorporate other factors such as efficacy and safety, social values and impact on health-related quality of life, cost-effectiveness data are still an important component of the decision-making process. The results from cost-effectiveness analysis for LMP in Europe suggest that its cost per QALY falls well below the accepted thresholds in those countries studied, and as such it provides value for money. These results highlight the importance of basing reimbursement decisions on health care resource use rather than simply on the direct cost of the treatment: LMP is more costly than other first-line treatments in PHN, but because of its superior side effect profile, users make fewer demands on other health care resources. This reduces overall costs and suggests LMP is highly cost-effective.

Clinical trial evidence supports the use of various pharmacological therapies for PHN, but the benefits of each agent need to be carefully balanced against the patient's underlying medical condition, age, and ability to tolerate side effects. Most patients with PHN are elderly, and polypharmacy is prevalent in this group of patients: for example, one study has identified that around $20 \%$ of people over the age of 70 years take five or more drugs at any one time. ${ }^{61}$ Polypharmacy is associated with increases in drug-drug interactions, adverse drug reactions, disease-drug interactions, and food-drug interactions. ${ }^{62}$ In addition, there is an associated increase in the prevalence of falls, ${ }^{63}$ hospital admission rates, length of hospital stay, readmission rates, and mortality rate. ${ }^{64} \mathrm{~A}$ topical therapy such as LMP, with proven efficacy and a very limited potential for systemic side effects and interactions with other medication,,$^{30,32-35}$ may offer a simple solution to these problems in elderly patients with PHN.

All modeling methods have limitations. The studies covered in this review were undertaken in different countries in Europe where disease management costs, health systems, and resource unit costs differ significantly. In addition, the availability of generic alternatives may have differed in these countries, and physicians may use different doses in different individuals. As a result, intercountry comparisons may not always be appropriate. Additionally, data used in the models have relied on clinical trials data available largely from indirect comparisons because direct comparison studies of all these agents for PHN have not been performed. For example, some of the earlier studies relative to pregabalin included in this review relied on noncomparative trials for model inputs and the inclusion of quality of life data from a variety of sources. However, later studies were based on a head-to-head trial and gave similar results, thereby providing a validation of the outcomes of the previous models. Lastly, the models have not considered combination treatment, even though this is relatively frequently used: in one study, $56 \%$ of PHN patients reported taking more than one prescription therapy in the past week. ${ }^{64}$

Despite differences in underlying clinical data, number of plasters, treatment patterns, costs, and clinical guidelines, there is remarkable similarity in cost-effectiveness of LMP across different countries and scenarios. Overall, the results from the ten studies covered in this review suggest that use of LMP offers cost savings compared with both gabapentin and pregabalin in elderly patients with PHN. These savings are largely the result of the positive safety profile of LMP, which drives the beneficial impact on quality of life and avoidance of costs related to adverse events and treatment discontinuations.

\section{Acknowledgment}

Editorial support in the development of this manuscript was provided by Adelphi Values and funded by Grünenthal $\mathrm{GmbH}$.

\section{Disclosure}

Hiltrud Liedgens and Marko Obradovic are employees of Grünenthal GmbH. Mark Nuijten has received consultancy fees from Grünenthal $\mathrm{GmbH}$ and other companies.

\section{References}

1. Johnson RW, Whitton TL. Management of herpes zoster (shingles) and postherpetic neuralgia. Expert Opin Pharmacother. 2004;5(3): 551-559.

2. Dworkin RH, Portenoy RK. Pain and its persistence in herpes zoster. Pain. 1996;67(2-3):241-251. 
3. Philip A, Thakur R. Post herpetic neuralgia. J Palliat Med. 2011; 14(6):765-773.

4. Lydick E, Epstein RS, Himmelberger D, White CJ. Herpes zoster and quality of life: a self-limited disease with severe impact. Neurology. 1995;45(12 Suppl 8):S52-S53.

5. Graff-Radford SB, Kames LD, Naliboff BD. Measure of psychological adjustment and perception of pain in postherpetic neuralgia and trigeminal neuralgia. Clin J Pain. 1986;2:55.

6. Volpi A. Severe complications of herpes zoster. Herpes. 2007; 14(Suppl 2):35-39.

7. Schmader KE. Epidemiology and impact on quality of life of postherpetic neuralgia and painful diabetic neuropathy. Clin J Pain. 2002; 18(6):350-354.

8. Gialloreti LE, Merito M, Pezzotti P, et al. Epidemiology and economic burden of herpes zoster and post-herpetic neuralgia in Italy: a retrospective, population-based study. BMC Infect Dis. 2010;10:230.

9. Dworkin RH, O'Connor AB, Backonja M, et al. Pharmacologic management of neuropathic pain: evidence-based recommendations. Pain. 2007;132(3):237-251.

10. Attal N, Cruccu G, Baron R, et al; European Federation of the Neurological Societies. EFNS guidelines on the pharmacological treatment of neuropathic pain: 2010 revision. Eur J Neurol. 2010;17(9): e1113-e1188.

11. Dubinsky RM, Kabbani H, El-Chami Z, Boutwell C, Ali H; Quality Standards Subcommittee of the American Academyof Neurology. Practice parameter: treatment of postherpetic neuralgia: an evidencebased report of the Quality Standards Subcommittee of the American Academy of Neurology. Neurology. 28 2004;63(6):959-965.

12. Douglas MW, Johnson RW, Cunningham AL. Tolerability of treatments for postherpetic neuralgia. Drug Saf. 2004;27(15):1217-1233.

13. Baron R, Mayoral V, Leijon G, Binder A, Steigerwald I, Serpell M. 5\% lidocaine medicated plaster versus pregabalin in postherpetic neuralgia and diabetic polyneuropathy: an open-label, noninferiority two-stage RCT study. Curr Med Res Opin. 2009;25(7): 1663-1676.

14. Hirsh AT, Atchison JW, Berger JJ, et al. Patient satisfaction with treatment for chronic pain: predictors and relationship to compliance. Clin J Pain. 2005;21(4):302-310.

15. Christo PJ, Hobelmann G, Maine DN. Post-herpetic neuralgia in older adults: evidence-based approaches to clinical management. Drugs Aging. 2007;24(1):1-19.

16. Vieweg WV, Wood MA. Tricyclic antidepressants, QT interval prolongation, and torsade de pointes. Psychosomatics. 2004;45(5): 371-377.

17. Vadalouca A, Siafaka I, Argyra E, Vrachnou E, Moka E. Therapeutic management of chronic neuropathic pain: an examination of pharmacologic treatment. Ann N Y Acad Sci. 2006;1088:164-186.

18. van Seventer R, Sadosky A, Lucero M, Dukes E. A cross-sectional survey of health state impairment and treatment patterns in patients with postherpetic neuralgia. Age Ageing. 2006;35(2): 132-137.

19. Beal B, Moeller-Bertram T, Schilling JM, Wallace MS. Gabapentin for once-daily treatment of post-herpetic neuralgia: a review. Clin Interv Aging. 2012;7:249-255.

20. Rowbotham M, Harden N, Stacey B, Bernstein P, Magnus-Miller L. Gabapentin for the treatment of postherpetic neuralgia: a randomized controlled trial. JAMA. 1998;280(21):1837-1842.

21. Rice AS, Maton S. Gabapentin in postherpetic neuralgia: a randomised, double blind, placebo controlled study. Pain. 2001;94(2): 215-224.

22. Bennett MI, Simpson KH. Gabapentin in the treatment of neuropathic pain. Palliat Med. 2004;18(1):5-11.

23. Pfizer. Lyrica ${ }^{\circledR}$ Summary of Product Characteristics. Available from: http://www.medicines.org.uk/emc/medicine/14651. Accessed September 16, 2013
24. Semel D, Murphy TK, Zlateva G, Cheung R, Emir B. Evaluation of the safety and efficacy of pregabalin in older patients with neuropathic pain: results from a pooled analysis of 11 clinical studies. BMC Fam Pract. 2010;11:85.

25. Dworkin RH, Corbin AE, Young JP Jr, et al. Pregabalin for the treatment of postherpetic neuralgia: a randomized, placebo-controlled trial. Neurology. 2003;60(8):1274-1283.

26. Sabatowski R, Galvez R, Cherry DA, et al. Pregabalin reduces pain and improves sleep and mood disturbances in patients with post-herpetic neuralgia: results of a randomised, placebo-controlled clinical trial. Pain. 2004;109(1-2):26-35.

27. Derry S, Lloyd R, Moore RA, McQuay HJ. Topical capsaicin for chronic neuropathic pain in adults. Cochrane Database Syst Rev. 2009;(4):CD007393.

28. Webster LR, Nunez M, Tark MD, et al. Tolerability of NGX-4010, a capsaicin $8 \%$ dermal patch, following pretreatment with lidocaine $2.5 \%$ / prilocaine $2.5 \%$ cream in patients with post-herpetic neuralgia. $B M C$ Anesthesiol. 2011;11:25.

29. Webster LR, Peppin JF, Murphy FT, Tobias JK, Vanhove GF. Tolerability of NGX-4010, a capsaicin $8 \%$ patch, in conjunction with three topical anesthetic formulations for the treatment of neuropathic pain. $J$ Pain Res. 2012;5:7-13.

30. Meier T, Wasner G, Faust M, et al. Efficacy of lidocaine patch $5 \%$ in the treatment of focal peripheral neuropathic pain syndromes: a randomized, double-blind, placebo-controlled study. Pain. 2003;106(1-2): $151-158$.

31. Rowbotham MC, Davies PS, Fields HL. Topical lidocaine gel relieves postherpetic neuralgia. Ann Neurol. 1995;37(2):246-253.

32. Rowbotham MC, Davies PS, Verkempinck C, Galer BS. Lidocaine patch: double-blind controlled study of a new treatment method for post-herpetic neuralgia. Pain. 1996;65(1):39-44.

33. Galer BS, Rowbotham MC, Perander J, Friedman E. Topical lidocaine patch relieves postherpetic neuralgia more effectively than a vehicle topical patch: results of an enriched enrollment study. Pain. 1999;80(3):533-538.

34. Galer BS, Jensen MP, Ma T, Davies PS, Rowbotham MC. The lidocaine patch $5 \%$ effectively treats all neuropathic pain qualities: results of a randomized, double-blind, vehicle-controlled, 3-week efficacy study with use of the neuropathic pain scale. Clin J Pain. 2002;18(5):297-301.

35. Binder A, Bruxelle J, Rogers P, Hans G, Bösl I, Baron R. Topical 5\% lidocaine (lignocaine) medicated plaster treatment for post-herpetic neuralgia: results of a double-blind, placebo-controlled, multinational efficacy and safety trial. Clin Drug Investig. 2009;29(6):393-408.

36. Argoff CE, Galer BS, Jensen MP, Oleka N, Gammaitoni AR. Effectiveness of the lidocaine patch $5 \%$ on pain qualities in three chronic pain states: assessment with the Neuropathic Pain Scale. Curr Med Res Opin. 2004;20 Supp1 2:S21-S28.

37. Katz NP, Gammaitoni AR, Davis MW, Dworkin RH. Lidocaine patch $5 \%$ reduces pain intensity and interference with quality of life in patients with postherpetic neuralgia: an effectiveness trial. Pain Med. 2002; 3(4):324-332.

38. Gammaitoni AR, Oleka N, Galer BS. Lidocaine patch 5\% improves outcomes for post-herpetic neuralgia patients receiving COX-2/antiinflammatory, opioid or adjuvant analgesics American Pain Society 24th Annual Scientific Meeting. 2005; Boston, MA, USA.

39. White RE, Hawkins, K. A comparative cost analysis on the use of lidocaine patch $5 \%$ and branded and generic gabapentin for treatment of chronic neuropathic and non-neuropathic pain conditions. Arthritis Rheum. 2005;52(9):S527.

40. Hans G, Sabatowski R, Binder A, Boesl I, Rogers P, Baron R. Efficacy and tolerability of a $5 \%$ lidocaine medicated plaster for the topical treatment of post-herpetic neuralgia: results of a long-term study. Curr Med Res Opin. 2009;25(5):1295-1305.

41. Galer BS, Gammaitoni AR. More than 7 years of consistent neuropathic pain relief in geriatric patients. Arch Intern Med. 2003; 163(5):628. 
42. Hempenstall K, Nurmikko TJ, Johnson RW, A'Hern RP, Rice AS Analgesic therapy in postherpetic neuralgia: a quantitative systematic review. PLoS Med. 2005;2(7):e164.

43. Wolff RF, Bala MM, Westwood M, Kessels AG, Kleijnen J. $5 \%$ lidocaine-medicated plaster vs other relevant interventions and placebo for post-herpetic neuralgia (PHN): a systematic review. Acta Neurol Scand. 2011;123(5):295-309.

44. Mick G, Correa-Illanes G. Topical pain management with the $5 \%$ lidocaine medicated plaster-a review. Curr Med Res Opin. 2012;28(6): 937-951.

45. Uberall MA, Müller-Schwefe GH. Patient perceptions associated with the $5 \%$ lidocaine medicated plaster in daily practice. Curr Med Res Opin. 2012;28(6):901-909.

46. Delorme C, Navez ML, Legout V, Deleens R, Moyse D. Treatment of neuropathic pain with 5\% lidocaine-medicated plaster: Five years of clinical experience. Pain Res Manag. 2011;16(4):259-263.

47. Sabatowski R, Hans G, Tacken I, Kapanadze S, Buchheister B, Baron R. Safety and efficacy outcomes of long-term treatment up to 4 years with $5 \%$ lidocaine medicated plaster in patients with postherpetic neuralgia. Curr Med Res Opin. 2012;28(8):1337-1346.

48. Dakin H, Nuijten M, Liedgens H, Nautrup BP. Cost-effectiveness of a lidocaine $5 \%$ medicated plaster relative to gabapentin for postherpetic neuralgia in the United Kingdom. Clin Ther. 2007;29(7):1491-1507.

49. Dakin H, Nuijten M, Liedgens H, Nautrup BP. Cost-utility analysis evaluating lidocaine $5 \%$ medicated plaster relative to gabapentin for postherpetic neuralgia in Scotland. Value Health. 2007;10(3): A9-A10.

50. Dakin H, Nuijten M, Poulsen Nautrup B, Liedgens H. Cost-effectiveness of a lidocaine plaster relative to pregabalin in the treatment of postherpetic neuralgia in Scotland. Value Health. 2007;10:A240.

51. Liedgens H, Hertel N, Gabriel A, et al. Cost-effectiveness analysis of a lidocaine $5 \%$ medicated plaster compared with gabapentin and pregabalin for treating postherpetic neuralgia: a German perspective. Clin Drug Investig. 2008;28(9):583-601.

52. Nuijten M, Pais BR, Liedgens H, van Wijck AJ. Cost-utility analysis evaluating the lidocaine $5 \%$ medicated plaster relative to gabapentin and pregabalin for post-herpetic neuralgia in The Netherlands. Value Health. 2008;11(5):A601.

53. Ritchie M, Liedgens H, Nuijten M. Cost effectiveness of a lidocaine $5 \%$ medicated plaster compared with pregabalin for the treatment of postherpetic neuralgia in the UK: a Markov model analysis. Clin Drug Investig. 2010;30(2):71-87.
54. Nuijten M, Hidalgo A, Obradovic M, Liedgens H. Cost-effectiveness of a lidocaine plaster relative to gabapentin and pregabalin in the treatment of postherpetic neuralgia in Spain. Value Health. 2010;13(7):A468.

55. Nuijten M, Gouveia M, Brandao J, Fleischhackl RH, Liedgens H. Cost-effectiveness of lidocaine $5 \%$ medicated plaster relative to pregabalin in the treatment of post-herpetic neuralgia in Austria and Portugal. Poster session presented at the 13th World Congress on Pain; 2010; Montréal, Canada. Available from: http://www. abstractsonline.com/Plan/ViewAbstract.aspx?sKey=2ec7e761 $\mathrm{d} 49 \mathrm{a}-463 \mathrm{~b}-\mathrm{ac} 8 \mathrm{f}-\mathrm{add} 5 \mathrm{cb} 56402 \mathrm{~d} \& \mathrm{cKey}=6 \mathrm{bca} 4996-\mathrm{f} 6 \mathrm{e} 0-49 \mathrm{cf}-$ $95 \mathrm{db}-857 \mathrm{fb} 675837 \mathrm{c} \& \mathrm{mKey}=\% 7 \mathrm{~b} 3 \mathrm{~F} 846 \mathrm{~F} 23-\mathrm{E} 219-40 \mathrm{~A} 0-\mathrm{B} 790$ DBC3F75684FD\%7d.

56. Nuijten M, Pais BR, Bergmann A, Liedgens H. Cost-utility analysis evaluating the lidocaine $5 \%$ medicated plaster relative to pregabalin for post-herpetic neuralgia in Sweden. Eur J Pain. 2010;Suppl 4(1):71.

57. Cepeda MS, Farrar JT. Economic evaluation of oral treatments for neuropathic pain. J Pain. 2006;7(2):119-128.

58. Armstrong EP, Malone DC, McCarberg B, Panarites CJ, Pham SV. Cost-effectiveness analysis of a new $8 \%$ capsaicin patch compared to existing therapies for postherpetic neuralgia. Curr Med Res Opin. 2011;27(5):939-950.

59. Smith KJ, Roberts MS. Sequential medication strategies for postherpetic neuralgia: a cost-effectiveness analysis. J Pain. 2007;8(5):396-404.

60. Kirson NY, Ivanova JI, Birnbaum HG, et al. Comparing healthcare costs of Medicaid patients with postherpetic neuralgia $(\mathrm{PHN})$ treated with lidocaine patch 5\% versus gabapentin or pregabalin. J Med Econ. 2010;13(3):482-491.

61. Rollason V, Vogt N. Reduction of polypharmacy in the elderly: a systematic review of the role of the pharmacist. Drugs Aging. 2003; 20(11):817-832.

62. Banerjee A, Mbamalu D, Ebrahimi S, Khan AA, Chan TF. The prevalence of polypharmacy in elderly attenders to an emergency department - a problem with a need for an effective solution. Int $J$ Emerg Med. 2011;4(1):22.

63. Ziere G, Dieleman JP, Hofman A, Pols HA, van der Cammen TJ, Stricker BH. Polypharmacy and falls in the middle age and elderly population. Br J Clin Pharmacol. 2006;61(2):218-223.

64. Di Legami V, Gianino MM, Ciofi degli Atti M, et al. Epidemiology and costs of herpes zoster: background data to estimate the impact of vaccination. Vaccine. 2007;25(43):7598-7604.
ClinicoEconomics and Outcomes Research

\section{Publish your work in this journal}

ClinicoEconomics \& Outcomes Research is an international, peerreviewed open-access journal focusing on Health Technology Assessment, Pharmacoeconomics and Outcomes Research in the areas of diagnosis, medical devices, and clinical, surgical and pharmacological intervention. The economic impact of health policy and health systems

\section{Dovepress}

organization also constitute important areas of coverage. The manuscript management system is completely online and includes a very quick and fair peer-review system, which is all easy to use. Visit http://www.dovepress.com/testimonials.php to read real quotes from published authors. 